\title{
SUPERAÇÃO DA DORMÊNCIA DE SEMENTES DE UMBUZEIRO (Spondias tuberosa, Arr. Câm.) UTILIZANDO DIFERENTES MÉTODOS ${ }^{1}$
}

\author{
PAULO SÉRGIO NASCIMENTO LOPES ${ }^{2}$, HÉLIDA MARA MAGALHÃES 3 , \\ JANAÍNA GONÇALVES GOMES ${ }^{4}$, DELACYR DA SILVA BRANDÃO JÚNIOR ${ }^{5}$, \\ VIRGÍNIA DUTRA DE ARAÚJO ${ }^{4}$
}

RESUMO-Vários frutos de espécies nativas da região semiárida possuem grande potencial de comercialização, dentre eles destaca-se o umbuzeiro (Spondias tuberosa, Arr. Câmara). Entretanto, cultivos comerciais desta espécie são limitados pela dificuldade da obtenção de mudas, em função principalmente da dormência de suas sementes. Desta forma, o objetivo do presente estudo foi avaliar os métodos de superação de dormência da semente de umbuzeiro, visando a promover incrementos nas taxas de germinação, uniformidade e vigor das plântulas. Foram montados dois experimentos independentes. Os tratamentos do primeiro experimento foram: testemunha, imersão dos pirênios em água por 24 horas, imersão dos pirênios em solução de ácido giberélico com $1.000 \mathrm{mg} / \mathrm{L}$ por 24 horas, escarificação dos pirênios com ácido sulfúrico PA por 10 minutos e escarificação mecânica. No segundo experimento, os tratamentos consistiram em se plantar os pirênios com $0 ; 30 ; 60 ; 90 ; 120 ; 150 ; 180$ e 210 dias de armazenados em sacos de papel sob condições de laboratório, a uma temperatura média de $22,5 \mathrm{C}^{\circ}$ e umidade relativa do ar média de $65 \%$. No primeiro estudo, constatou-se que houve efeito significativo dos métodos de superação de dormência, sendo que escarificação mecânica foi o que apresentou os melhores resultados, com uma taxa de germinação média aos 60 dias pós-plantio de $26,6 \%$. Já no segundo, as sementes armazenadas influenciaram positivamente na germinação e no vigor da plântula. Os melhores resultados para uniformidade e porcentagem de germinação (83\%) foram obtidos entre 120 e 210 dias de armazenamento das sementes, enquanto para o comprimento e massa fresca da radícula e hipocótilo foram entre 120 e 150 dias.

Termos para indexação: escarificação, ácido giberélico, armazenamento de pirênios, umbu, propagação, germinação.

\section{OVERCOMING DORMANCY OF 'UMBUZEIRO' SEEDS (Spondias tuberosa, Arr. Câm.) BY USING DIFFERENT METHODS}

\begin{abstract}
Several fruits of native species of semi-arid region have great potential for commercialization, and among them there is the Spondias tuberosa. However, commercial cultivation of this species is limited by the difficulty of obtaining seedlings mainly depending on the dormancy of its seeds. Thus, the purpose of this study was to evaluate the seeds overcoming dormancy methods of Spondias Tuberosa to promote an increase in the rates of germination, uniformity and vigor of the seedlings. Two experiments were independently conducted. The treatments of the first experiments were: test, immersion of the seeds in water for 24 hours, immersion of the seeds in solution of gibberellic acid $1000 \mathrm{mg} / \mathrm{L}$ for 24 hours, scarification of seeds with sulfuric acid PA for 10 minutes and mechanical scarification of seeds. In the second experiment, the treatments consisted of planting the seeds with $0,30,60,90,120,150,180$ and 210 days of storage in paper bags under laboratory conditions, at an average temperature of $22.5^{\circ} \mathrm{C}$ and relative humidity of $65 \%$. In the first study it was found that there was a significant effect of the methods to seeds overcoming dormancy, concluding that the mechanical scarification is the best treatment, with an average germination rate in 60 days after planting $26.6 \%$. In the second experiment, storage positively influenced the germination of seeds and seedlings vigor. The best results for uniformity and germination percentage $(83 \%)$ were obtained between 120 and 210 days of seeds storage, while for the length and fresh weight of root, between 120 and 150 days.
\end{abstract}

Index terms: scarification, gibberellic acid, seeds storage, "umbu", propagation, germination.

${ }^{1}$ (Trabalho 214-08). Recebido em:15-08-2008. Aceito para publicação em: 13-01-2009.

${ }^{2}$ Pós-Doutorando (Bolsista Capes/PROCAD: edital 01/2007) e Prof. Adjunto do Instituto de Ciências Agrárias, UFMG, CEP: 39.404006, CP: 135, Montes Claros-MG, e-mail: psnlopes@ufmg.br

${ }^{3}$ Enga Agr., Mestranda em Ciências Agrárias do Inst. de Ciências Agrárias, UFMG, CEP: 39.404-006, CP: 135, Montes Claros-MG, e-mail: helidamara@hotmail.com.

${ }^{4}$ Acadêmicas do curso de Agronomia do Inst. de Ciências Agrárias, UFMG, CEP: 39.404-006, CP: 135, Montes Claros-MG, e-mail: gomesjg13@yahoo.com.br e viginex111@yahoo.com.br.

${ }^{5}$ Prof. Adjunto do Inst. de Ciências Agrárias, UFMG, CEP: 39.404-006, CP: 135, Montes Claros-MG. e-mail: dsbrandraojr@ufmg.br. 


\section{INTRODUÇÃO}

O umbuzeiro (Spondias tuberosa, Arr. Câmara) é uma planta nativa da região semiárida, sendo seus frutos consumidos in natura ou de forma processada, como na fabricação de sucos, doces, sorvetes e licores, além de serem aproveitados na alimentação animal (Cavalcanti et al., 1997).

Um dos fatores que dificultam a propagação do umbuzeiro em larga escala é a dormência das suas sementes, o que propicia uma emergência lenta e desuniforme, conforme constatado por alguns autores (Araújo et al., 2001; Costa et al., 2001; Souza et al., 2005).

A semente de umbuzeiro está envolvida por endocarpo rígido, lenhoso e lignificado (Cardoso, 1992). Para Campos (1986) e Carvalho \& Nakagawa (2000), o endocarpo resistente impede o crescimento e a expansão do embrião, além de restringir a entrada de água e oxigênio no interior da semente. A formação de sementes duras contribui para a distribuição temporal da germinação, o que reduz os riscos da emergência simultânea e permite, também, manter a sobrevivência das sementes durante a passagem pelo trato digestivo dos animais. Entretanto, essas sementes tornam-se indesejáveis para produção de mudas, porque provocam a germinação irregular e a maturação desuniforme das plantas, comprometendo o estabelecimento do estande (Marcos Filho, 2005). A dormência da semente do umbuzeiro é considerada primária, ou seja, um fenômeno geneticamente programado para surgir e desenvolver-se juntamente com a mesma (Cavalcanti \& Rezende, 2005).

Há diversas maneiras de acelerar e uniformizar a germinação das sementes. Uma delas seria o uso de tratamentos pré-germinativos, como: imersão em água, escarificação química e mecânica, reguladores de crescimento, entre outras. Outra seria submeter as sementes do umbuzeiro a um período de armazenamento, que é, em muitos casos, utilizado como método prático de superação de dormência de sementes (Marcos Filho, 2005).

Para o umbuzeiro, existem alguns trabalhos que investigaram a superação de dormência da suas sementes, tendo como melhores resultados a escarificação mecânica (Campos, 1986) e o armazenamento de pirênios (Araújo et al., 2001; Souza et al., 2005; Cavalcanti et al., 2006). Entretanto, a escarificação mecânica é um método trabalhoso e oneroso, pois exige que cada semente seja tratada individualmente, utilizando-se de ferramentas como torno e serras (Campos, 1986) ou tesouras de podas com aço muito resistente e afiado. Quanto ao armazenamento, apesar de ser um método simples, limita o plantio das sementes a determinadas épocas do ano, como obtido por Souza et al. (2005), que, recomendam o plantio do pirênio após 08 meses de armazenamento Araújo et al. (2001) após 24 meses e Cavalcanti et al. (2006) entre 24 e 36 meses. Neste sentido, torna-se importante desenvolver estudos com outros métodos, comparando-os aos já existentes, com o intuito de simplificar e permitir o plantio da semente de umbuzeiro em qualquer época do ano. Sugerem-se a imersão em água, o uso de regulador de crescimento e a escarificação química que podem apresentar respostas positivas na quebra de dormência de semente envolvida por endocarpo duro.

Malavasi \& Malavasi (2004), ao avaliarem o uso da escarificação mecânica, diferentes concentrações de ácido sulfúrico e embebição em água na superação da dormência de sementes de timburi (Enterobium contortisiliquum), verificaram que as maiores taxas de germinação e vigor foram obtidas com a escarificação química em ácido sulfúrico concentrado por 180 minutos. Também, Travlos et al. (2007) e Barbosa et al. (2005) verificaram o efeito positivo do ácido sulfúrico sobre a superação da dormência das sementes de Tylosema esculentum e Strelizia reginae. Já o uso do ácido giberélico também estimulou a germinação em Allocasuarina campestris, Regelia ciliata, Xanthorrhoea gracilis, Xanthorrea preissii (Bell et al., 1995) e em sementes de atemóia (Annona cherimola $\mathrm{x}$ Annona squamosa), nas dosagens de 50 ou 100 ppm (Stenzel et al., 2003).

Dessa forma, objetivou-se neste trabalho avaliar os métodos de superação de dormência da semente de umbuzeiro, visando a promover incrementos nas taxas de germinação, uniformidade e vigor das plântulas.

\section{MATERIAL E MÉTODOS}

Os experimentos foram conduzidos no Laboratório de Análise de Sementes do Núcleo de Ciências Agrárias - Universidade Federal de Minas Gerais (LAS/NCA - UFMG), localizado no Câmpus Regional de Montes Claros-MG.

As sementes foram coletadas em janeiro de 2007, na região de Porteirinha - MG. Os frutos encontravam-se em estádio maduro. A polpa foi retirada com auxílio de uma despolpadora, colocandose os pirênios para secar por seis dias à sombra. Após isso, os pirênios foram selecionados, descartando-se aqueles que possuíam algum dano mecânico ou sintomas de ataque de pragas e doenças.

O primeiro experimento foi montado em delineamento inteiramente casualizado, em parcela subdividida no tempo, com cinco tratamentos na 
parcela, quatro na subparcela (épocas de avaliações), seis repetições e 25 sementes em cada unidade experimental. Os tratamentos na parcela foram: testemunha (nenhum tratamento pré-germinativo), imersão das sementes em água por 24 horas mantidas sob oxigenação, imersão das sementes em uma solução de ácido giberélico com $1.000 \mathrm{mg} / \mathrm{L}$ por 24 horas mantidas sob oxigenação no escuro, a uma temperatura de $24,9 \mathrm{C}^{\circ}$, escarificação das sementes com ácido sulfúrico PA por 10 minutos e escarificação mecânica. A escarificação mecânica foi feita na parte distal do pirênio, com auxílio de motoesmeril em aproximadamente $5 \mathrm{~mm}$ do endocarpo, tomando-se o cuidado de não ferir o endosperma. Os tratamentos na subparcela foram avaliações feitas aos $15 ; 30 ; 45$ e 60 dias pós-plantio.

As sementes foram semeadas entre papel germitest, previamente umedecido com água destilada na proporção de 2,5 vezes o peso seco do papel, sendo em seguida colocadas para germinar em germinador modelo Mangelsdorf, a uma temperatura de $25^{\circ} \mathrm{C}$ constante. $\mathrm{O}$ papel germitest foi trocado uma vez aos trinta dias pós-plantio.

As avaliações para germinação foram feitas diariamente, obtendo-se ao final de cada período $(15,30,45$ e 60 dias do início do teste) o total em percentagem das sementes germinadas. As sementes foram consideradas germinadas quando apresentavam protusão (emissão) de estruturas essenciais do embrião. $\mathrm{O}$ índice de velocidade de germinação foi calculado pela forma de Maguire, citado por Carvalho (1994), contabilizando-se diariamente a quantidade de sementes germinadas até 60 dias após a semeadura.

O segundo experimento foi conduzido em delineamento inteiramente casualizado, com 08 tratamentos e quatro repetições, sendo utilizadas 20 sementes por parcela. Os tratamentos constituíram em 08 épocas de armazenamento $(0 ; 30 ; 60 ; 90 ; 120$; $150 ; 180$ e 210 dias), sendo as sementes armazenadas em sacos de papel e mantidas em condições de laboratório, em uma temperatura média de $22,5 \mathrm{C}^{\circ} \mathrm{e}$ umidade relativa do ar média de $65 \%$. A cada 30 dias, as sementes foram semeadas nas mesmas condições do experimento anterior.

Após 30 dias do início de cada tratamento, foram avaliados a germinação final, o índice de velocidade de germinação (IVG), o comprimento e a massa fresca do hipocótilo e a radícula. A percentagem de germinação e o IVG foram realizados diariamente, considerando a protusão de estruturas essenciais do embrião. O índice de velocidade de germinação foi estimado igual ao primeiro trabalho. O tamanho e a massa do hipocótilo e da radícula foram determinados com auxílio de uma régua e balança de precisão.

Visando a caracterizar o lote das sementes, foi determinada a massa de 1.000 pirênios e a umidade pelo método da estufa $105 \mathrm{C}^{\circ} \pm 3 \mathrm{C}^{\circ}$ (Brasil, 1992). A umidade no primeiro experimento foi verificada por meio de amostras com dez pirênios e três repetições, enquanto no segundo, com dez pirênios e duas repetições em todas as épocas de plantio. A massa e a umidade na instalação do primeiro e segundo experimentos são, respectivamente: $269,75 \mathrm{~g}$ e $23,13 \%$, e $334,25 \mathrm{~g}$ e $41,5 \%$. Os pirênios utilizados nos dois experimentos apresentaram boa uniformidade quanto ao peso, pois nos dois casos o coeficiente de variação (CV) é baixo 3,74 (experimento 1) e 3,32 (experimento 2). Segundo Brasil (1992), os lotes de sementes que apresentam o CV até $4,0 \%$ quanto ao peso de 1.000 sementes são considerados homogêneos.

Os dados foram submetidos à análise de variância e, posteriormente, quando qualitativos, as médias comparadas pelo teste de Tukey $(p<0,05)$ e quando quantitativos por regressão polinomial $(p<0,05)$. Os dados percentuais de germinação foram transformados em arc-sen $\sqrt{\frac{x}{100}}$

\section{RESULTADOS E DISCUSSÃO}

\section{Experimento 1: Efeitos dos tratamentos pré-germinativos}

Houve efeitos significativos da interação tratamento x época. $O$ tratamento com escarificação mecânica foi o que apresentou o melhor resultado como método para superar a dormência em todas as épocas avaliadas, seguido das sementes tratadas com ácido giberélico (Tabela 1). Esse comportamento superior das sementes escarificadas mecanicamente também foi verificado para o índice de velocidade de germinação (IVG) aos 60 dias pós-plantio (Tabela 1), o que já era esperado, pois sementes que possuem maior germinação em diferentes épocas de avaliação também apresentam maior IVG.

Resultados similares foram encontrados por Campos (1986) que, estudando sementes de umbuzeiro cortadas em formato de bisel, verificou que somente o corte foi suficiente para promover a germinação. Cruz et al. (2001), trabalhando com sementes de jatobá, Hymenaea intermedia, verificaram que a escarificação mecânica constitui um método eficiente para superar a dormência e promover a germinação de sementes.

Por outro lado, apesar de o tratamento com escarificação mecânica proporcionar uma taxa de germinação mais do que o dobro do uso do ácido giberélico, este último gerou resultados bem superiores 
aos demais tratamentos (Tabela 1), principalmente a partir da segunda época, indicando provavelmente que existe mais de um mecanismo de dormência no caso do umbuzeiro, como relatado por Lederman et al. (1989).

A escarificação mecânica pode ter facilitado a expansão do embrião ou ainda a liberação de substâncias inibidoras solúveis em água presentes na região interna ao endocarpo para o ambiente (Marcos Filho, 2005). Já a ação do ácido giberélico poderia estar associada ao balanço de substâncias promotoras e inibidoras da germinação, assim como influencia no controle de hidrólise de reservas pela indução da $\alpha$ amilase, enzima responsável pela hidrólise do amido. O ácido giberélico é considerado ativador enzimático endógeno, promove a germinação e a aplicação exógena deste promotor e influencia no metabolismo proteico, podendo dobrar a taxa de síntese de proteínas das sementes (Alvarenga, 2004).

As sementes sem nenhum tratamento (testemunha) e as imersas em água por 24 horas não diferiram estatisticamente entre si. Costa et al. (2001), estudando o estádio de maturação das sementes de umbuzeiro em diferentes tempos de pré-embebição em água ( $0 ; 48 ; 96$ e 114 horas), concluíram não haver influência dos períodos de imersão em água sobre a germinação de sementes de umbuzeiro. Isto reforça que o efeito da imersão em solução do ácido giberélico se deve à giberelina e não à água.

Quanto à escarificação química, ela foi ineficiente em propiciar incrementos na germinação das sementes de umbuzeiro. Provavelmente, o tempo e a concentração de ácido sulfúrico utilizados podem ter provocado alguma injúria ao embrião, impedindo assim a sua germinação.

Em relação às épocas de avaliação, elas influenciaram nas sementes que sofreram escarificação mecânica e nas tratadas com ácido giberélico, ajustando-se à equação do tipo modelo linear. Já as sementes que foram imersas em água e sem nenhum tratamento não foram significativas quanto às épocas de avaliação (Figura 1).

A avaliação da germinação aos 15 dias coincidiu com os resultados do IVG aos 60 dias pós-plantio, podendo assim ser um bom parâmetro de verificação do vigor de sementes do umbuzeiro, pois, apesar de aos 60 dias os tratamentos proporcionarem às sementes maiores valores de germinação, houve a necessidade de troca do papel, o que amplia os custos e a causa de variação da análise.

\section{do pirênio \\ Experimento 2: Efeito do armazenamento}

O gráfico de porcentagem de umidade assumiu modelo quadrático, sendo que as sementes no início estavam com umidade em torno de $40 \%$, e na última época de armazenamento, de $11,57 \%$, sendo que, a partir dos 60 dias, a umidade se manteve quase que constante, apresentando um pequeno aumento em função provavelmente das condições ambientais (Figura 2).

As sementes armazenadas por mais tempo alcançaram porcentagens de germinação maiores. As épocas $0 ; 30$ e 60 dias proporcionam baixos índices. As melhores épocas que proporcionaram incrementos de germinação compreendem os períodos de 120 a 210 dias (Figura 3), alcançando 83\% de germinação.

A curva do índice de velocidade de germinação assumiu modelo linear. O índice passou de 0,01675 no início para 2,6562 na última época de armazenamento (Figura 4). Resultados similares foram encontrados por Souza et al. (2005), estudando quatro estádios de maturação e armazenamento de sementes de umbuzeiro, concluindo que o maior tempo de armazenamento, oito meses, foi o que proporcionou melhor velocidade e índice de germinação das sementes. Também Araújo (2001) e Cavalcanti et al. (2006) verificaram que a dormência de semente de umbuzeiro é mais bem superada durante o seu armazenamento por 24 a 36 meses.

Segundo Marcos Filho (2005), o armazenamento de sementes supera todas as causas de dormência, como: controle do equilíbrio entre substâncias promotoras e inibidoras do crescimento, resistência mecânica da cobertura, dormência do embrião, impermeabilidade da cobertura a gases e água, bem como combinação de causas.

Quanto ao comprimento e à massa da matéria fresca do hipocótilo e da radícula, estes seguiram uma tendência quadrática. As sementes recém-armazenadas tiveram ganhos gradativos de comprimento ao longo das épocas de armazenamento $(0 ; 30 ; 60$ e 90 dias), ocorrendo posterior declínio aos 122 dias para o hipocótilo e aos 125 dias para a radícula (Figuras 5 e 6). Resultado semelhante foi obtido com relação à massa da matéria fresca do hipocótilo com ganhos crescentes até 173 dias, sendo que, a partir daí, ocorreu declínio (Figura 7). Quanto à massa da matéria fresca da radícula, este valor foi crescente, com tendência a se manter constante a partir das épocas de 180 e 210 dias (Figura 8). Esse desempenho do hipocótilo e da radícula demonstra que, reduzindo o efeito da dormência, ocorre aumento no vigor da plântula. Souza et al. (2005) verificaram que, quanto mais a dormência era superada, maior torna-se a altura 
de plântulas.

O comportamento crescente do comprimento e da massa da matéria fresca do hipocótilo e da radícula ao longo das primeiras épocas de armazenamento está relacionado, provavelmente, a baixa e lenta germinação das sementes de umbuzeiro, em decorrência da dormência destas. A gradativa superação da dormência das sementes durante o armazenamento, independentemente da causa dessa dormência, promove também um aumento gradativo no vigor das plântulas. Um exemplo disso é que, na presença de doses crescentes de substâncias inibidoras da germinação, ocorre decréscimo significativo do desenvolvimento da plântula, conforme constatado por Rosa et al. (2006) no cultivo in vitro de embriões de Coffea submetidos a diferentes concentrações de cafeína.

Já o declínio no crescimento do hipocótilo e da radícula, após determinado período, pode ser reflexo da deterioração das sementes. Souza et al. (2005), avaliando a influência do efeito da embalagem (saco de papel e de polietileno), ambiente de armazenamento (laboratório e geladeira) e período de armazenamento $(0 ; 30 ; 60 ; 90 ; 120$ e 150$)$ sobre o vigor de sementes de ipê-amarelo (Tabebuia serratifolia), verificaram que as sementes armazenadas em sacos de papel e em laboratório apresentaram redução do vigor ao longo do tempo de armazenamento. $\mathrm{O}$ autor justificou estes resultados na deterioração das sementes. Com o envelhecimento das sementes, as membranas perdem a permeabilidade seletiva, as enzimas tornam-se menos eficientes para exercer sua atividade catalítica; também tem sido destacada a decomposição das reservas, ocorrendo ainda o acúmulo de produtos tóxicos que prejudicam o desempenho das sementes (Marcos Filho, 2005).

TABELA 1- Porcentagem de germinação (\% G) e índice de velocidade na germinação (IVG) de sementes de umbuzeiro submetidas a diferentes tratamentos (testemunha, ácido giberélico GA 3 escarificação mecânica, imersão das sementes em água, escarificação química (ácido sulfúrico PA), dentro de cada época de avaliação pós-plantio. Montes Claros- MG, 2007.

\begin{tabular}{|c|c|c|c|c|c|}
\hline \multirow{2}{*}{ Tratamentos } & \multicolumn{4}{|c|}{ Épocas de Avaliações \% G } & \multirow{2}{*}{ IVG* } \\
\hline & E15 & E30 & E45 & E60 & \\
\hline Test & $0,0 \mathrm{~b}$ & $0,0 \mathrm{c}$ & $0,0 \mathrm{c}$ & $1,3 \mathrm{c} \mathrm{d}$ & $0,0580 \mathrm{~b}$ \\
\hline Ác. giberélico & $0,6 \mathrm{~b}$ & $5,3 \mathrm{~b}$ & $6,6 \mathrm{~b}$ & $11,3 \mathrm{~b}$ & $0,0907 \mathrm{~b}$ \\
\hline Esc. Mecânica & $18,6 \mathrm{a}$ & $21,3 \mathrm{a}$ & $26,6 \mathrm{a}$ & $26,6 \mathrm{a}$ & $0,7160 \mathrm{a}$ \\
\hline Esc. Química & $0,0 \mathrm{~b}$ & $0,0 \mathrm{c}$ & $0,0 \mathrm{c}$ & $0,0 \mathrm{~d}$ & $0,0000 \mathrm{~b}$ \\
\hline Água & $0,0 \mathrm{~b}$ & $0,0 \mathrm{c}$ & $3,3 \mathrm{c}$ & $3,3 \mathrm{c}$ & $0,0153 \mathrm{~b}$ \\
\hline Média & 3,84 & 5,32 & 6,64 & 8,5 & 0,176 \\
\hline CV \% & 36,28 & 36,28 & 36,28 & 36,28 & 89,0 \\
\hline
\end{tabular}

OBS: As médias seguidas da mesma letra minúscula na coluna não diferem entre si, pelo teste de Tukey, ao nível de 5\% de probabilidade. *O IVG aos 60 dias.

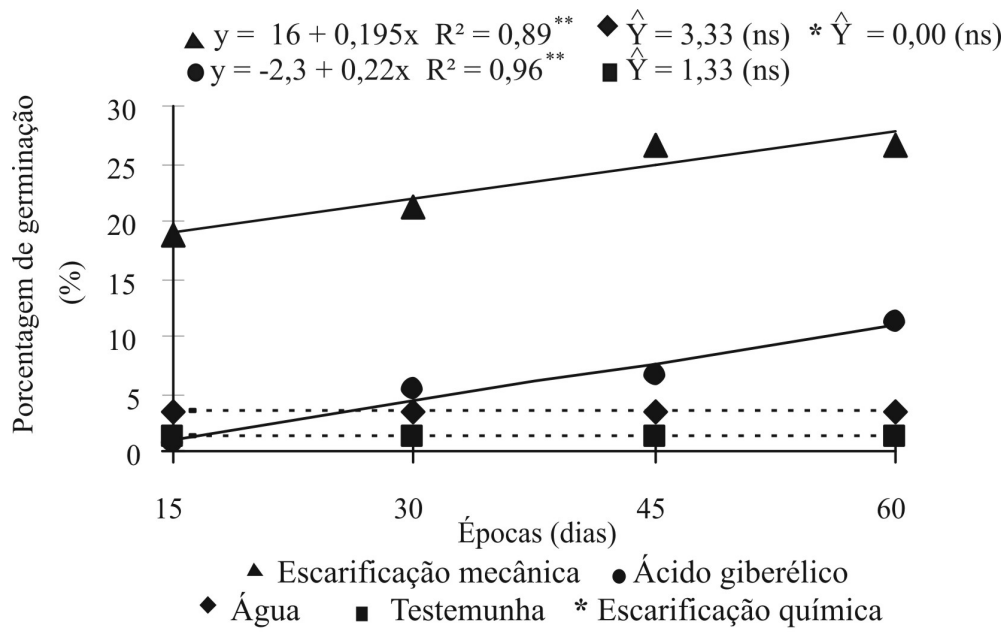

FIGURA 1- Porcentagem de sementes germinadas de umbuzeiro em função de diferentes épocas de avaliações em cada tratamento utilizado para quebra de dormência. (testemunha, ácido giberélico GA3, escarificação mecânica e química, imersão das sementes em água).Montes ClarosMG, 2007. 


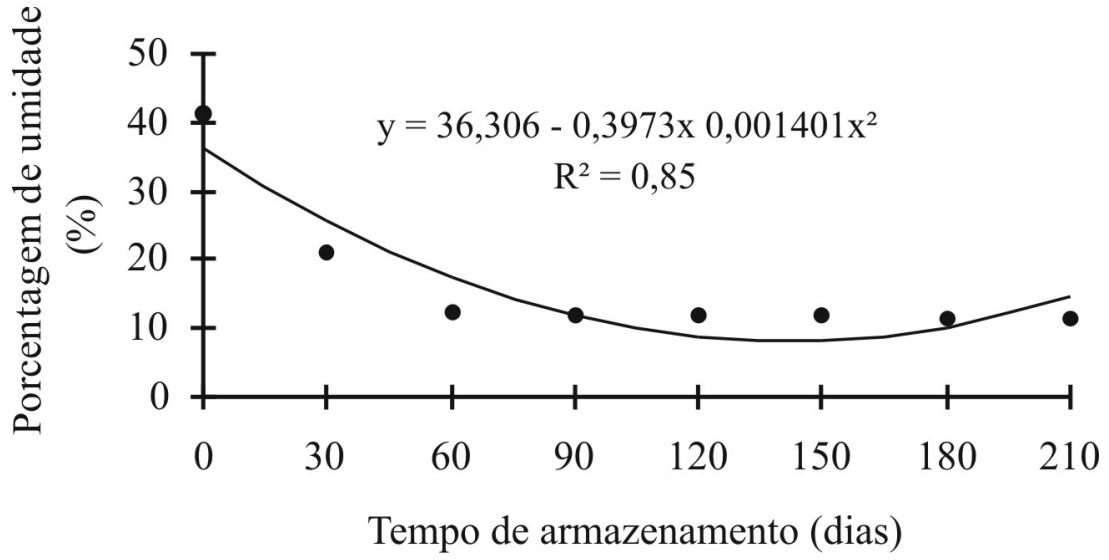

FIGURA 2 - Porcentagem de umidade de sementes de umbuzeiro em função dos períodos de armazenamento. Montes Claros- MG, 2007.

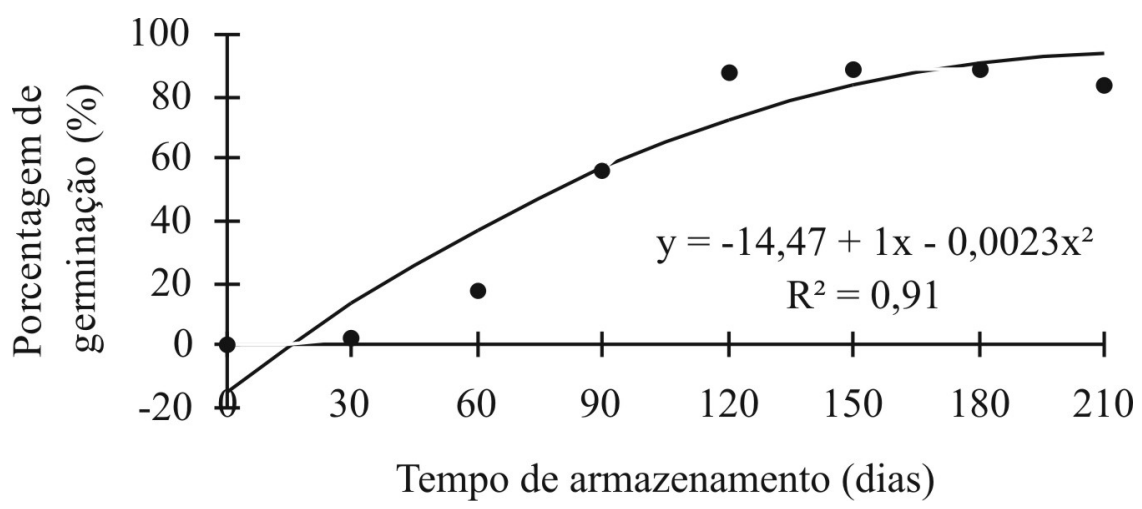

FIGURA 3 - Porcentagem de sementes germinadas de umbuzeiro em função de diferentes tempos de armazenamento.Montes Claros- MG, 2007.

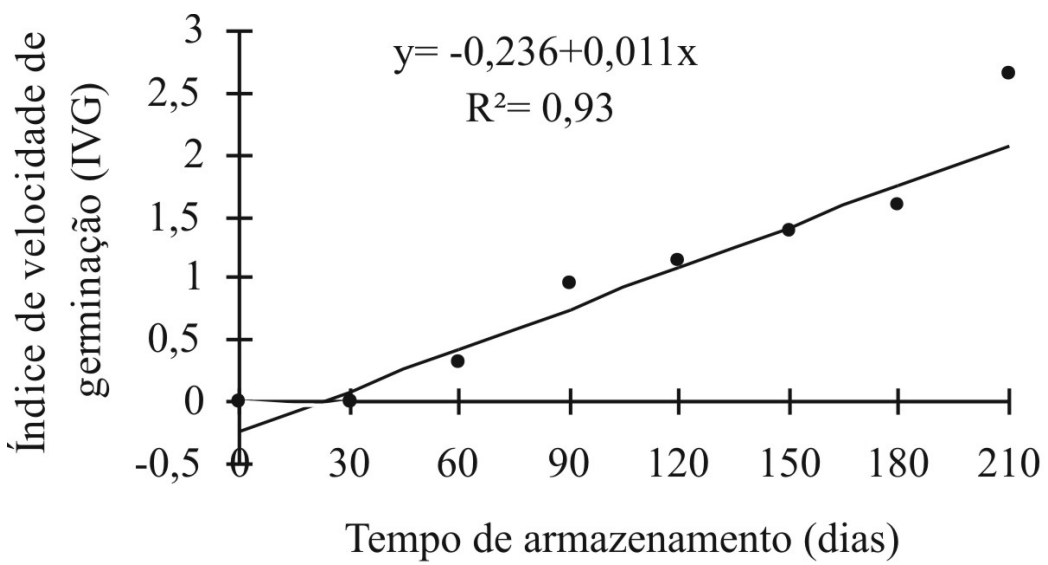

FIGURA 4 - Índice de velocidade de germinação (IVG) de sementes de umbuzeiro em função de diferentes tempos de armazenamento.Montes Claros- MG, 2007. 


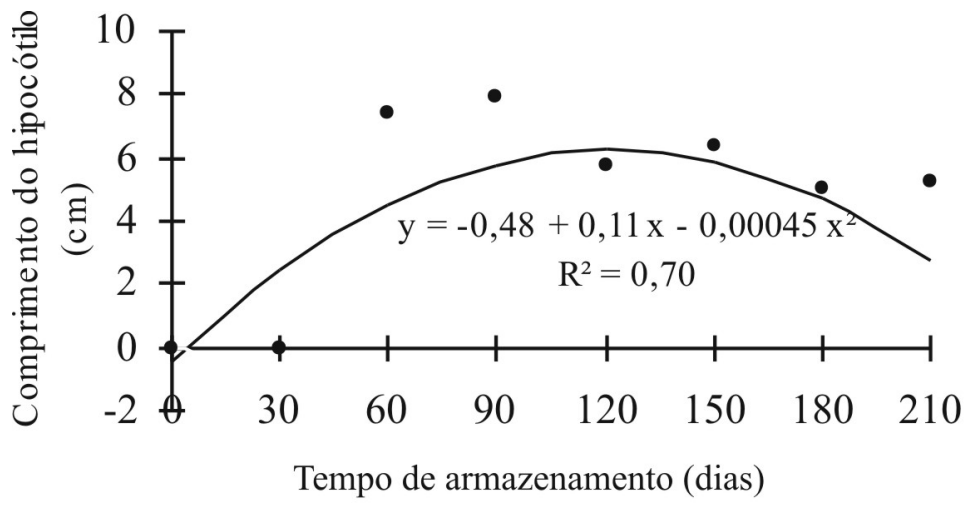

FIGURA 5 - Comprimento do hipocótilo de sementes de umbuzeiro em função de diferentes tempos de armazenamento. Montes Claros- MG, 2007.

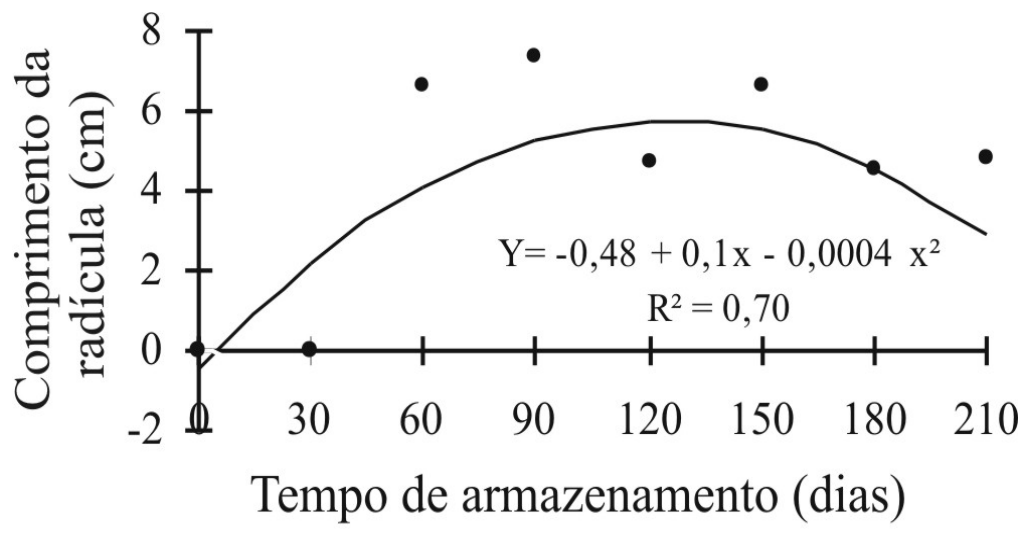

FIGURA 6 - Comprimento da radícula de sementes de umbuzeiro em função de diferentes tempos de armazenamento.Montes Claros- MG, 2007.

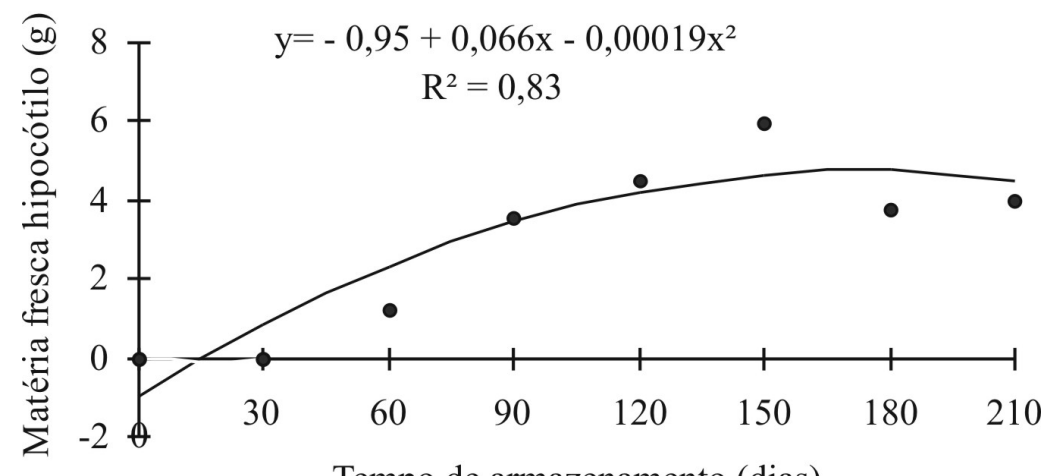

Tempo de armazenamento (dias)

FIGURA 7 - Massa da matéria fresca do hipocótilo de sementes de umbuzeiro em função de diferentes tempos de armazenamento.Montes Claros- MG, 2007. 


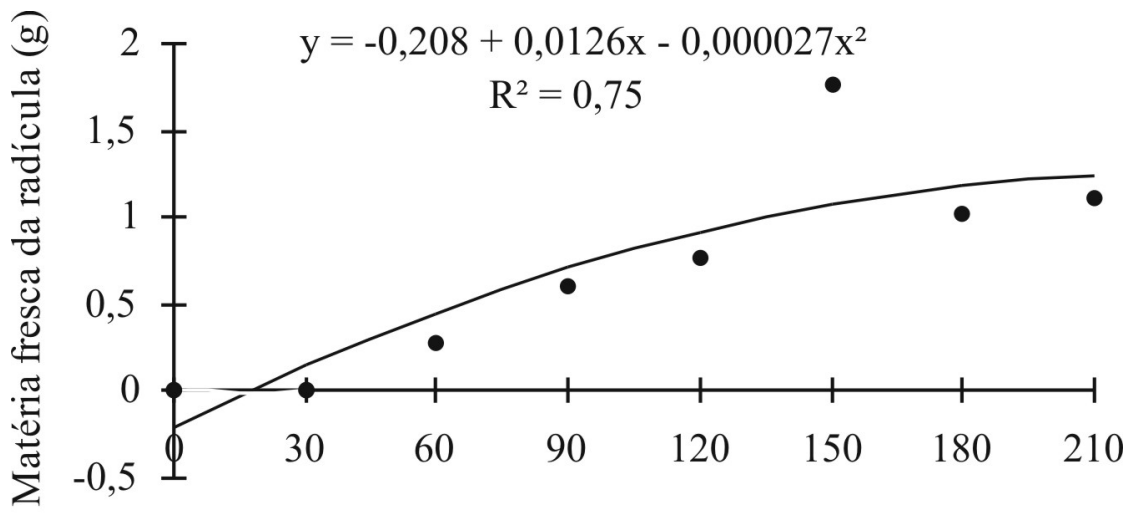

\section{Tempo de armazenamento (dias)}

FIGURA 8 - Massa da matéria fresca da radícula de sementes de umbuzeiro em função de diferentes tempos de armazenamento.Montes Claros- MG, 2007.

\section{CONCLUSÕES}

1-A escarificação mecânica foi o tratamento mais eficiente em quebrar a dormência das sementes de umbuzeiro, seguida do tratamento com uso de ácido giberélico.

2-O armazenamento das sementes entre 120 e 210 dias foi o mais adequado a uma maior uniformidade e percentual de germinação.

3-O armazenamento das sementes entre $120 \mathrm{e}$ 150 dias garante maior comprimento e massa fresca da raiz e hipocótilo.

\section{AGRADECIMENTOS}

Ao Centro de Agricultura Alternativa de Montes Claros/CAA-MG, pela doação das sementes de umbuzeiro.

\section{REFERÊNCIAS}

ALVARENGA, A.A. Fitohormônios e fitorreguladores. Lavras: UFLA, 2004. 42p. (Textos Acadêmicos, 45).

ARAÚJO, F. P.; SANTOS, C.A. F.; CAVALCANTI, N. B.; REZENDE, G. M. Influência do período de armazenamento das sementes de umbuzeiro na sua germinação e no desenvolvimento de plântula. Revista Brasileira de Armazenamento, Viçosa, v.1, n.26, p.36-39, 2001.

BARBOSA, J. G.; ALVARENGA, E. M.; SANTOS, D.C.F.; DIAS, A.N.V. Efeito da escarificação ácida e de diferentes temperaturas na qualidade fisiológica de sementes de strelitzia reginae. Revista Brasileira de Sementes, Brasília, v. 27, n. 1, p.71-77, 2005.

BELL, D. T.; ROKICH, D. P.; MCCHESNEY, C. J.; PLUMMER, J. A. Effects of temperature, light an gibberellic acid on the germination of seeds of 43 species native to western Australia. Sweden, Journal of Vegetation Science, Washington, v.6, n.6, p.797-806,1995.

BRASIL. Ministério da Agricultura e Reforma Agrária. Regras para análises de sementes. Brasília: SNDA/DND/CLAV, 1992. 365p.

CAMPOS, C. de O. Estudo da quebra de dormência da semente de umbuzeiro (Spondias tuberosa Arr. Câm.) 1986. 71 f. Dissertação (Mestrado em Agronomia) - Centro de Ciências Agrárias, Universidade Federal Ceará, Fortaleza,1986.

CARDOSO, E. A. Germinação, morfologia e embriologia de algumas espécies do gênero Spondias. 1992. 58f. Dissertação (Mestrado em Produção Vegetal) - Centro de Ciências Agrárias, Universidade Federal da Paraíba, Areia, 1992.

CARVALHO, N. M. O conceito de vigor em sementes. In: VIEIRA R.D.; CARVALHO, N.M. Testes de vigor em sementes. Jaboticabal: FUNEP, 1994. p.30.

CARVALHO, N. M.; NAKAGAWA, A. J. Sementes ciência tecnologia e produção. 4. ed. Jaboticabal: FUNEP, 2000. 588p. 
CAVALCANTI, N. B.; RESENDE, G. M.; BRITO, L. T. de L.; CHOUDHURY, M. M. Aproveitamento alimentar do imbuzeiro (Spondias tuberosa, Arr. Cam.) no semiárido do Nordeste brasileiro. In: SIMPÓSIO LATINO-AMERICANO DE CIÊNCIA DE ALIMENTOS, 2., 1997. Campinas - SP. Anais... Campinas : Unicamp, 1997. p. 395.

CAVALCANTI, N. B.; RESENDE, G. M. Influência de diferentes substratos na emergência de plântulas de imbuzeiro. Revista Caatinga, Mossoró, v.18, n.1, p.22-27, 2005.

CAVALCANTI, N. B.; RESENDE, G. M.; DRUMND, M.A. Período de dormência de sementes de imbuzeiro. Revista Caatinga, Mossoró, v.19, n.2, p.135-139, 2006.

COSTA, N. P. da; BRUNO, R. L. A.; SOUZA, F. X.; LIMA, E. D. P. A. Efeito do estádio de maturação do fruto e do tempo de pré-embebição de endocarpos na germinação de sementes de umbuzeiro (Spondias tuberosa Arr. Câm.). Revista Brasileira de Fruticultura, Jaboticabal, v. 23, n. 3, p.738-741, 2001.

CRUZ, E. D.; MARTINS, F. de.O.; CARVALHO, J. E. U. de. Biometria de frutos e sementes e germinação de jatobá-curuba (Hymenaea intermedia Ducke, Leguminosae - Caesalpinioideae). Revista Brasileira de Botânica, São Paulo, v. 24, n. 2, p.161-165, 2001.

LEDERMAN, E. I.; NETO, L.G.; BEZERRA, J. E. F. B. Indução da germinação de sementes de umbu (Spondias tuberosa arr. Cam.) através de tratamentos físicos, químicos e mecânicos. Revista Brasileira de Fruticultura, Jaboticabal, v.11, n. 3, p.27-32, 1989.
MALAVASI, U. C.; MALAVASI, M. M. Dormancy breaking and germination of Enterolobium contortisiliquum (Vell.) Morong seed. Brazilian Archives of Biology and Technology, Curitiba, v. 47, n. 6, p. 851-854, 2004.

MARCOS FILHO, J. Fisiologia de sementes de plantas cultivadas. In: JULHO, M.F. Dormência de sementes. Piracicaba: Fealq, 2005. p.253-287.

SOUZA, A. A. de; BRUNO, R. L. A.; LOPES, K. P.; CARDOSO, G.D.; PEREIRA, W. E.; FILHO, J. C. Semillas de Spondias tuberosa oriundos de frutos cosechados en cuatro estadios de maturación y almacenadas. Revista Brasileira de Engenharia Agrícola e Ambiental, Campina Grande, v.9, n. 3 , p. $372-378,2005$

ROSA, S.D.V.F. da; SANTOS, C.G. dos; PAIVA, R.; MELO, P.L.Q. de; VEIGA, A.D. Inibição do desenvolvimento in vitro de embriões de Coffea por cafeína exógena. Revista Brasileira de Sementes, Brasilia, v.28, n.3, p.177-184, 2006.

SOUZA, V. C de; BRUNO, R. L. A.; ANDRADE, L. A. Vigor de sementes armazenadas de ipê-amarelo Tabebuia serratifolia. Revista Árvore, Viçosa, v. 29, n. 6, p. 833-841, 2005.

STENZEL, N. M. C.; MURATA, I. M.; NEVES, C. S. V. J. Superação da dormência em sementes de atemóia e fruta-do-conde. Revista Brasileira de Fruticultura, Jaboticabal, v.25, n.2, p.305-308, 2003.

TRAVLOS, I.S.; ECONOMOU, G.; KARAMANOS, A. I. Germination and emergence of the hard seed coated Tylosema esculentum (Burch) A. Schereib in response to different pre-sowing seed treatments. Journal of Arid Environments ,Athens, v.68, p.501-507, 2007. 